kích thước u không phải là yếu tố liên quan tới sống thêm [6].

Giai đoạn bệnh là yếu tố tiên lượng quan trọng ảnh hưởng đến thời gian sống thêm sau mổ. Tuy nhiên chúng tôi chưa thấy mối liên quan giữa thời gian sống thêm và giai đoạn bệnh. Điêu này có thể là do cỡ mẫu nghiên cứu còn nhỏ.

Bênh nhân có bênh tim mach kèm theo có thời gian sống thêm trung bình là $37,45 \pm 3,5$ tháng thấp hơn so với thời gian sống thêm trung bình của nhóm không có bênh tim mach kèm theo $(51,8 \pm 1,8$ tháng). Sư khác biêt có ý nghĩa thống kê với $p<0,05$. Do bệnh nhân bệnh lý tim mạch thường phục hồi sau mổ chậm hơn, ảnh hưởng đến liều và liệu trình điều trị hóa chất bổ trợ sau mổ

\section{KẾT LUÂN}

Hóa trị bổ trợ phác đồ EOX đem lại lợi ích sống thêm trên bệnh nhân cao tuổi ung thư dạ dày đã phẫu thuật triệt căn có nguy cơ cao với tỳ lệ sống thêm toàn bộ ước tính theo Kaplan Meier sau 3 năm, 4 năm và 5 năm tương ứng là $85,6 \%, 59,7 \%$, 46,7\%, tỷ lệ sống thêm không bệnh sau 3 năm, 4 năm và 5 năm ước tính tương ứng là $63,5 \%, 45,8 \%$ và $35,6 \%$.

\section{TÀI LIÊU THAM KHẢO}

1. World Health Organization (2018). Gastric Cancer. International Agency for Research on Cancer, GLOBOCAN 2018.

2. Vũ Hải (2009), Nghiên cứu chỉ đinh các phương pháp phâu thuật, hoá chất bổ trợ và đánh giá kêt quả điêu trị ung thư da dày tai Bệnh viện K, Luận án Tiến sĩ y học, Học viện Quẩn y.

3. Phan Cảnh Duy (2019), "Kết quả điêu trị ung thư biểu mô tuyến da day phân xa da dày giai đoạn tiến triển tại chố bằng phấu thuật kết hợp xạ - hóa sau mổ", Tap chí Y họ lâm sàng, Bênh viện Trung Ương Huể, số 55, tr: $80-88$.

4. Vũ Quang Toản, Đoàn Hữu Nghi, Đỗ Anh Tú (2015), Điều trị ung thư dạ dày tiên triển tại chô bằng phẫu thuật và hóa trị bổ trợ EOX, Tạp chí Y hoc lâm sàng, số 29/2015, 270-278.

5. Bang Y.-J., Kim Y.-W., Yang H.-K. et al (2012). Adjuvant capecitabine and oxaliplatin for gastric cancer after D2 gastrectomy (CLASSIC): a phase 3 open-label, randomised controlled trial. The Lancet, 379(9813), 315-321.

6. Fukuda N., Sugiyama Y., Wada J. (2011). Prognostic factors of T4 gastric cancer patients undergoing potentially curative resection. World journal of gastroenterology: WJG, 17(9), 1180.

\title{
CÁC YẾU TỐ LIÊN QUAN ĐẾN TÁI PHÁT MUỘN SAU ĐộT QUỴ THIẾU MÁU NÃO CẤP TẠI TIỀN GIANG
}

\section{TÓM TẮT}

Mở đâu: Nguy cơ tái phát muộn sau đột quy thiếu máu não cấp thì vẫn còn cao mặc dù đã có những cải thiện trong chiến lược phòng ngữa đột quy thứ phát. Việc xác định tỉ suất tái phát đột quy muộn và các yễu tố liên quan đến nguy cơ tái phát đột quy muộn vẫn còn han chế. Muc tiêu nghiên cứu: Xác đinh tỷ suất tái phát đột quỵ tích lũy tại thời điểm 1 năm và các yếu tố liên quan độc lập đến tái phát muôn sau đột quy thiếu máu não cấp. Phương pháp nghiên cứu: Nghiên cứu đoàn hê quan sát, tiền cứu. Sử dung ước tính Kaplan-Meier và mô hình hồi quy Cox để xác định tỷ suất tái phát đột quy tích lũy và các yếu tố liên quan độc lập đến nguy cơ tái phát muộn sau đột quy. thiếu máu não cuc bô cấp. Kết quả: Trong 2 năm, chúng tôi thu thập được 520 bệnh nhân đột quỵ thiếu máu não cục bộ cấp và theo dõi 1 năm. Tỷ suất tái phát đột quỵ tích lũy tại thời điểm 1 năm là $21,2 \%$.

\footnotetext{
*Bệnh viện Đa khoa Trung tâm Tiền Giang

**Đai hoc Y dước Thành phố Hồ Chí Minh.

Chịu trách nhiệm chính: Nguyễn Văn Dũng

Email: dungbvtg@gmail.com

Ngày nhận bài: 12.3.2021

Ngày phản biên khoa hoc: 11.5.2021

Ngày duyệt bài: 17.5.2021
}

\section{Nguyễn Văn Dũng*, Cao Phi Phong**}

Các yếu tố liên quan độc lập với đột quy tái phát bao gồm trình độ học vấn, tiền sử đột quy./TIA, tiền sử nhồi máu cơ tim, rung nhĩ, lấp mạch tứ tim và dùng thuốc statin. Kết luân: Tỷ suất tái phát đôt quy tích lũy tai thời điểm 1 năm là 21,2\%. Các yếu tố liên quan đốc lập với đột quy tái phát là trình độ học vấn, tiền sử đột quy./TIA, tiền sử nhồi máu cơ tim, rung nhĩ, lấp mach từ tim và dùng thuốc statin.

Tư khóa: yếu tố, tái phát muộn, liên quan, đột quỵ thiếu máu não cấp.

\section{SUMMARY \\ FACTORS ASSOCIATED WITH LATE RECURRENCE AFTER ACUTE ISCHEMIC STROKE IN TIEN GIANG}

Background: The risk of late recurrence after acute ischemic stroke remains high despite improvements in secondary stroke prevention strategies. The determination of late stroke recurrence rate and factors associated with to late stroke recurrence is still limited. Objectives: Determine the cumulative stroke recurrence rate at 1 year and factors independently associated with to the risk of late recurrence after acute ischemic stroke. Methods: Prospective, observational cohort study. Using KaplanMeier estimation and Cox regression model to determine the cumulative stroke recurrence rate and 
factors associated with the risk of late recurrence after acute ischemic stroke. Results: In 2 years, we collected 520 patients with acute ischemic stroke and followed up for 1 year. The cumulative stroke recurrence rate at 1 year was $21.2 \%$. Factors independently associated with recurrent stroke include education level, history of stroke/TIA, history of myocardial infarction, atrial fibrillation, cardioembolism and use statin drug. Conclusions: The cumulative stroke recurrence rate at 1 year was $21.2 \%$. Factors independently associated with recurrent stroke were education level, history of stroke/TIA, history of myocardial infarction, atrial fibrillation, cardioembolism and use statin drug.

Keywords: factor, late recurrence, associated with, acute ischemic stroke.

\section{I. ĐĂT VẤN ĐỀ}

Đôt quy tái phát sau đột quy thiếu máu não cấp thường dẫn đến tỉ lệ tử vong cao hơn, mức độ tàn tật lớn hơn, chi phí điều trị tăng lên so với biến cố đột quy lần đâu. Mặc dù đã có những cải thiên trong chiến lược phòng ngừa đột quy. tái phát nhưng tỉ lê tái phát đột quy muộn vần còn cao. Thật vậy, theo Wang và cộng sự thì tỉ lệ đột quy tái phát taii thời điểm 1 nămm là $17,7 \%$. Mắt khác, theo Hankey và cộng sự thì tỉ suất đột quy. tái phát tích lũy tại thời điểm 6 tháng và 5 năm lần lượt là $8,8 \%$ và $22,5 \%$.

Trển thế giới, có nhiêu nghiên cứu về đột quy. tái phát với thời gian theo dõi là 1 năm. Tuy nhiên, ở Việt Nam nói chung và miền Tây Nam Bộ nói riêng, số lượng nghiên cứu về vấn đề này với thời gian theo dõi 1 năm còn hạn chế. Vì vậy, chúng tôi tiến hình nghiên cứu đề tài " Các yếu tố liên quan đến tái phát muộn sau đột quy thiếu máu não cấp tại Tiên Giang" với các mục tiêu sau đây:

- Xác định tỷ suất tái phát đột quy tích lũy tại thời điểm 1 năm.

- Xác định các yếu tố liên quan độc lập đến tái phát muộn sau đột quy thiêu máu não câp.

II. ĐỐI TƯợNG VÀ PHƯƠNG PHÁP NGHIÊN CỨU

Đối tượng nghiên cứu: Đó là những bênh nhân đột quỵ thiếu máu não cục bộ cấp nhập vào khoa Nôi Thần Kinh, bênh viện ĐKTT Tiền Giang từ tháng 02 năm 2016 đến tháng 7 năm 2017 có đủ tiêu chuẩn chon mấu.

Tiêu chuẩn chọn mấu:

Tiêu chuẩn chọn vào: Bệnh nhân được chẩn đoán xác định là đột quy thiếu máu nã̃o cuc bồ cấp theo tiêu chuẩn lấm sàng của Tổ chức $Y$ tế Thế giới và hình ảnh chụp cắt lớp vi tính/cộng hưởng từ sọ não, đồng thời có địa chỉ rõ ràng và/hoăc số điện thoai.

\section{Tiêu chuẩn loai ra:}

- Bệnh nhân có tiền sử đột quỵ nhưng lần này nhập viện điều trị vì bệnh khác.

- Bệnh nhân không làm đầy đủ các cận lâm sàng cần thiết.

- Bệnh nhân chấn thương hoặc phẫu thuật trong vòng 3 ngày trước khi đột quy khởi phát, bệnh gan mức độ nặng, bệnh nhiếm khuẩn cấp lúc nhâp viên.

- Bệnh nhân không đồng ý tham gia nghiên cứu.

\section{Phương pháp nghiên cứu:}

Thiết kế nghiên cứu: Nghiên cứu đoàn hệ quan sát, tiến cứu.

Phương pháp chọn mẫu: Chọn liên tiếp những bệnh nhân được chẩn đoán là đột quy. thiếu máu não cấp vào khoa Nội Thần Kinh bệnh viện ĐKTT Tiền Giang trong thời gian nghiên cứu và phải đảm bảo cõ̃ mẫu tối thiểu cho nghiên cứu.

Cõ̃ mẫu: Được tính theo công thức dành cho nghiên cứu đoàn hê, tiến cứu có sử dụng phương pháp phân tích sống còn. Cõ̃ mẫu tối thiểu là 330 bênh nhân.

\section{Phương pháp thu thập số liệu:}

- Thu thập thông tin khi bệnh nhân nhập viện: Những bệnh nhân đột quy thiếu máu não cấp được khám lâm sàng tỉ mi và cho làm đầy đủ các cận lâm sàng cần thiết để thu thập các thông tin cho nghiên cứu. Đồng thời, ghi nhận số điện thoại của bệnh nhân và người nhà bệnh nhân.

- Chúng tôi tiến hành theo dõi tái phát đột quỵ ngay lúc bệnh nhân còn nằm viện.

- Sau khi ra viện: chúng tôi tiếp tục theo dõi bênh nhân thông qua khám trực tiếp hoặc gọi điện thoại cho đến khi kết thúc nghiên cứu. Thời gian theo dõi sau ra viện là 1 năm.

- Tất cả những thông tin thu thâp đều được ghi nhận cẩn thân vào bảng thu thâp sổ liệu có sẵn.

Phương pháp xử lý số liệu: Số liệu được nhâp, mã hóa và xử lý bằng phẩn mềm thống kê SPSS 20.0. Ước tính Kaplan-Meier và mô hình hồi quy Cox được sử dung để tính tỷ suất tái phát tích lũy tại thời điểm 1 năm và xác định các yếu tố liên quan độc lập với đột quy tái phát.

\section{KẾT QUẢ NGHIÊN CỨU}

\section{Đăc điểm chung của dân số nghiên cứu}

Các yếu tố về dân số họ. Thực tế chúng tôi thu thập được 520 bệnh nhân. Trong đó, tỉ lệ nam giới và nữ giới gần bằng nhau. Tuổi trung bình của các bênh nhân là $69 \pm 12,5$ với tuổi nhỏ nhất là 26 và tuổi lớn nhất là 96 , trong đó gần $2 / 3$ bệnh nhân thuộc nhóm tuổi $\geq 65$. Gần 3/4 số bệnh nhân trong nghiên cứu sống ở khu vực nông thôn và chỉ có $1 / 4$ số bênh nhân trong nghiên cứu của chúng tôi có trình độ trên tiểu học. 
VIETNAM MEDICAL JOURNAL N01 - JUNE - 2021

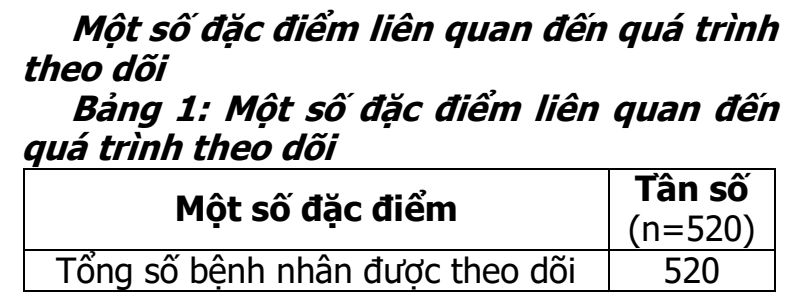

Bảng 2: Các yếu tồ dân số học và tiền sử

\begin{tabular}{|c|c|c|c|}
\hline Yếu tố nguy cơ & HR & KTC 95\% & Giá trị p \\
\hline Tuối $\geq 65$ & 1,93 & $1,26-2,97$ & 0,003 \\
\hline Giới nữ & 1,34 & $0,92-1,94$ & 0,128 \\
\hline Trình độ học vấn (tiêú học trở xuống) & 2,90 & $1,63-5,16$ & $<0,001$ \\
\hline Tình trạng hôn nhân (sống 1 mình) & 1,10 & $0,75-1,60$ & 0,627 \\
\hline Tiền sử tăng huyết áp & 1,04 & $0,70-1,55$ & 0,842 \\
\hline Tiền sử đái tháo đường & 1,17 & $0,71-1,94$ & 0,537 \\
\hline Tiền sứ đột quy./TIA & 1,83 & $1,24-2,68$ & 0,002 \\
\hline Tiền sử gia đình có người thân bị đột quỵ. & 0,69 & $0,41-1,15$ & 0,153 \\
\hline Tiền sử nhồi máu cơ tim & 4,91 & $2,88-8,36$ & $<0,001$ \\
\hline
\end{tabular}

Bảng 3: Các yếu tố nguy cơ mạch máu

\begin{tabular}{|c|c|c|c|}
\hline Yếu tố nguy cơ & HR & KTC 95\% & Giá trị p \\
\hline Tăng huyết áp & 1,21 & $0,75-1,97$ & 0,435 \\
\hline Đái tháo đường & 1,07 & $0,66-1,72$ & 0,788 \\
\hline Rối loạn lipid máu & 1,07 & $0,71-1,60$ & 0,754 \\
\hline Rung nhĩ & 2,17 & $1,36-3,46$ & 0,001 \\
\hline Tập thế dục & 0,45 & $0,23-0,88$ & 0,020 \\
\hline Hút thuốc lá & 0.89 & $0,58-1,36$ & 0,594 \\
\hline Uống rượu & 0.90 & $0,58-1,40$ & 0,649 \\
\hline Hẹp van hai lá & 0,92 & $0,23-3,73$ & 0.909 \\
\hline Hẹp van động mạch chủ $\geq 70 \%$ & 1,44 & $0,73-2,85$ & 0,294 \\
\hline
\end{tabular}

Bảng 4: Các yếu tố lâm sàng, cận lâm sàng, nguyên nhân theo phân loại TOAST và điều trị sau ra viện

\section{Yếu tố nguy cơ}

HA tâm thu lúc nhập viện $\geq 140 \mathrm{mmHg}$

HA tâm trương lúc nhập viện $\geq 90 \mathrm{mmHg}$ Điểm Glasgow lúc nhập viên $\leq 8$

Điểm NIHSS lúc nhập viện: 5 đến 24

$$
\geq 25
$$

Điếm Rankin hiệu chỉnh lúc ra viện $>2$

Nồng đô cholesterol toàn phần cao

Nồng độ triglyceric cao

Nồng độ LDL-C cao

Nồng độ HDL-C thấp

Nồng độ hs-CRP cao trên $>3 \mathrm{mg} / \mathrm{L}$

Lấp mạch từ tim (TOAST)

Thuốc chống kết tập tiếu cầu

Thuốc statin

Thuốc hạ huyết áp

\section{HR}

bênh nhân tái phát

Số bệnh nhân mất theo dõi

Thời gian theo dõi (năm)

Tỉ suất tái phát đột quy tích lũy tại tời điểm 1

năm sau đột quy thiếu máu não cấp là $21,2 \%$

Kết quả phân tích đơn biến 


\begin{tabular}{|c|c|c|c|}
\hline Tiên sử đột quy./TIA & 1,88 & $1,27-2,78$ & 0,002 \\
\hline Tiền sử nhồi máu cơ tim & 3,30 & $1,88-5,79$ & $<0,001$ \\
\hline Rung nhĩ & 1,74 & $1,05-2,87$ & 0,031 \\
\hline Tập thể dục & 0,57 & $0,28-1,16$ & 0,122 \\
\hline iiểm Rankin lúc ra viện & 1,32 & $0,57-3,06$ & 0,523 \\
\hline hs-CRP >3mg/L & 1,16 & $0,77-1,75$ & 0,484 \\
\hline HATT lúc nhâ̂p viện. & 1,40 & $0,92-2,15$ & 0,121 \\
\hline Điếm NIHSS lúc nhập viện $\geq 15$ & 1,08 & $0,43-2,75$ & 0,868 \\
\hline Dùng thuốc chống kê̂t tập tiếu cầu & 1,03 & $0,60-1,76$ & 0,912 \\
\hline Dùng thuốc statin & 0,62 & $0,42-0,92$ & 0.016 \\
\hline Lấp mạch từ tim (TOAST) & 1,85 & $1,05-3,24$ & 0,032 \\
\hline
\end{tabular}

\section{BÀN LUÂ̂N}

Tỉ suất tái phát tích lũy tại thời điểm 1 năm sau đột quy. thiếu máu não cấp

Qua quan sát các nghiên cứu, chúng tôi nhận thấy đột quy tái phát xảy ra nhiều nhất trong năm đẩu tiên. Những năm sau đó, nguy cơ tái phát đột quy. trung bình hàng năm sẽ giảm dần. Kết quả từ nghiên cứu của chúng tôi cho thấy tỷ suất tái phát đột quỵ tích lũy tại thời điểm 1 năm sau đột quy thiếu máu não là $21,2 \%$. Kết quả này cao hơn hầu hết các nghiên cứu khác. Điển hình, nghiên cứu của Xu và cộng sự thì tỷ suất tái phát sau 1 năm là $11,2 \%$ [8], nghiên cứu của Mohan và cộng sự thì tỷ suất này là $11,1 \%$ [6] và vài nghiên cứu khác cũng có tỷ suất thấp hơn của chúng tôi. Tuy nhiên, vẫn có một số nghiên cứu có tỷ suất tái phát đột quỵ tích lũy tại thời điểm 1 năm ở mức gần bằng với kết quả của chúng tôi. Chẳng hạn, theo kết quả nghiên cứu của Hardie và cộng sự là $16 \%$. Bên cạnh, nghiên cứu Wang và cộng sự ở Trung Quốc thì tỷ suất này là $17,7 \%$. Ngoài ra, theo Viitanen và cộng sự đã cho thấy kết quả lên đến $18 \%$.

Tỷ suất đột quỵ tái phát tùy thuộc vào nhiều yếu tố, chẳng hạn như nghiên cứu đó dựa vào bệnh viện hay cộng đồng, đối tượng nghiên cứu, đinh nghĩa đôt quy tái phát, thiết kế nghiên cứu và chiến lược phòng ngừa đột quy thứ phát...Nhìn chung, tỷ suất tái phát tại thời điểm 1 năm sau đột quy thiếu máu não còn cao. Điều này nhắc nhở chúng ta cần đưa ra chiến lược phòng ngừa đột quỵ. thứ phát một cách hợp lý, kịp thời và hiệu quả.

Một số yếu tố liên quan đến đột quỵ tái phát

Tuổi: Tuổi là yếu tố nền tảng, được các tác giả đề cập trong hầu hết các nghiên cứu. Trong nghiên cứu của chúng tôi, tuổi không có liên quan độc lập với nguy cơ tái phát đột quy. Kết quả này tương tự với vài nghiên cứu khác. Thật vậy, theo Burn và cộng sự thì tuổi không có liên quan đến nguy cơ tái phát đột quy. Bên cạnh, một số nghiên cứu cũng cho kết quả tương tự [8].
Trình độ học vấn: Trong nghiên cứu này, trình độ học vẩn thấp < 6 năm (tiểu học trở xuống) là yễu tố liên quan độc lập với sự gia tăng nguy cơ tái phát đột quỵ với $\mathrm{HR}=1,97 ; \mathrm{p}=$ 0,030 . Kết quả này tương tự với nghiên cứu của Melkas và cộng sự. Kết quả từ nghiên cứu của tác giả này cho thấy trình độ học vấn thấp làm tăng nguy cơ đột quy tái phát với $\mathrm{HR}=1,42 ; \mathrm{p}$ $=0,070$ [5]. Thêm vào đó, nghiên cứu của Che và cộng sự thấy rằng trình độ học vấn $<6$ năm làm tăng nguy cơ đột quy tái phát với $H R=$ 1,73 . Thật vậy, trình độ học vấn thấp có ảnh hưởng đển đột quỵ từ nhiều mặt, chẳng hạn nhu khả năng tìm hiểu về đột quỵ, nhận biết yếu tô nguy cơ và triệu chứng đột quỵ, sự tuân thủ trong điều trị đột quy.

Tiền sử đột quy./TIA: Kết quả từ nghiên cứu của chúng tôi cho thây tiền sử đột quy hoặc TIA là yếu tố liên quan độc lập với sự gia tăng nguy cơ tái phát đột quy với $H R=1,88 ; p=0,002$. Kết quả này phù hợp với nhiều nghiên cứu khác. Điển hình, trong nghiên cứu của Alter và cộng sự, tiền sử ít nhất 1 lần bị TIA sẽ làm tăng nguy cơ tái phát đột quy lên đến 41,4 lần [2].

Tiền sử nhôi máu cơ tim: Trong nghiên cứu của chúng tôi, tiền sử nhồi máu cơ tim có liên quan độc lập làm tăng nguy cơ tái phát đột quy. với $H R=3,30 ; p=<0,001$. Kết quả này tướng tự với những nghiên cứu khác. Điển hình trong số đó là nghiên cứu của tác giả Prencipe và cộng sự tại Ý, tiền sử nhồi máu cơ tim làm tăng nguy cơ đột quy tái phát với $H R=2,9$. Mặt khác, theo tác giả Aitter và cộng sự thì tiền sử nhồi máu cơ tim làm tăng nguy cơ đột quy tái phát với $R R=8.0$ [2]. Có thể giải thích tiền sử nhồi máu cơ tim làm tăng nguy cơ đột quy tái phát vì hai bệnh này có chung nền tảng xơ vữa mạch máu.

Tăng huyết áp: Trong nghiên cứu của chúng tôi, tăng huyết áp không có liên quan với nguy cơ tái phát đột quy. Tăng huyết áp là yếu tố không có sự đồng nhất giữa các nghiên cứu. 
Kết quả này phù hợp với vài nghiên cứu cho rằng tăng hyết áp không làm tăng nguy cơ đột quy tái phát. Chẳng hạn, theo Wang và cộng sự thì không có sự khác nhau giữa nhóm có và không có tăng huyết áp đối với nguy cơ đột quy. tái phát tại thời điểm 1 năm (18\% so với $17 \%$, p $=0,21$ ). Trái lại, có những nghiên cứu cho rằng tăng huyết áp làm tăng nguy cơ đột quy tái phát. Điển hình, nghiên cứu của Xu và cônng sự cho rằng tăng huyết áp không kiểm soát sẽ làm tăng nguy cơ đột quy tái phát với $H R=3,15, p$ $<0,001$. Việc không xác định tăng huyết áp như một yếu tố dự báo tái phát đột quy có thể phản ánh rằng nguy cơ cao ở những bệnh nhân đã mắc bệnh nào đó sẽ lấn át bất kỳ ảnh hưởng nào của môt yếu tố nguy cơ cu thể.

Đái tháo đường: Trong nghiên cứu của chúng tôi, đái tháo đường không phải là yếu tố có liên quan độc lập với nguy cơ tái phát đột quy. Đái tháo đường cũng là yếu tố được nhiều tác giả tranh luận đối với nguy cơ tái phát đột quy. Nhìn chung những nghiên cứu có thời gian theo dõi không quá 2 năm thì đái tháo đường sẽ không có liên quan độc lập với tăng nguy cơ đột quỵ tái phát. Điển hình là nghiên cứu của Alter và cộng sự [1], nghiên của của Xu và cộng sự [8] đều cho kết quả tương tự như nghiên cứu của chúng tôi. Tuy nhiên, những nghiên cứu có thời gian theo dõi từ 3 đến 5 năm thì thấy rằng đái tháo đường có liên quan độc lập với tăng nguy cơ đột quỵ tái phát. Chẳng hạn, nghiên cứu của Petty và cộng sự, nghiên cứu của Putaala và cộng sự đều thấy rằng đái tháo đường có liên quan độc lập với nguy cơ tái phát đột quy.

Rối loạn lipid máu: Kết quả nghiên cứu cho thấy rối loạn lipid máu không có liên quan độc lập với nguy cơ tái phát đôt quy. Kết quả của chúng tôi tương tự với nghiên cứu của Prencipe và cộng sự, nghiển cứu của Patel và cộng sự. Bên cạnh, nghiên cứu của Arboix và cộng sự thấy rằng nhóm có tăng lipid máu làm giảm nguy cơ đột quy với $O R=0,52$. Như vậy, mối liên quan giữa rối loạn lipid máu với đột quy tái phát chưa thật sự rõ ràng, cần có những nghiên cứu sâu hơn nữa trong tương lai.

Rung nhĩ: Trong nghiên cứu này, rung nhĩ là một trong những yếu tố liên quan độc lập với sự gia tăng nguy cơ tái phát đột quy với $\mathrm{HR}=1,74$; $p=0,031$. Kết quả này tương đồng với nhiều nghiên cứu khác. Cụ thể, nghiên cứu của $X u$ và cộng sự thấy rằng rung nhĩ không kiểm soát làm tăng nguy cơ đột quy tái phát với $\mathrm{HR}=4,70 ; \mathrm{p}$ $<0,001$ [8]. Hơn nữa, tác giả Penado và cộng sự thấy rằng trong số những bệnh nhân rung nhĩ không dùng kháng đông sẽ bị đột quy tái phát cao hơn nhóm có dùng kháng đông ( $27 \%$ so với $18 \%$ ) [7]. Từ kết quả này chúng ta thây rõ được tầm quan trọng của việc dùng kháng đông trển đối tượng đột quy thiếu máu não có rung nhĩ trong việc phòng ngừa đột quỵ thứ phát.

Phân nhóm nguyên nhân đột quỵ thiếu máu não theo phân loại TOAST: Trong nghiên cứu của chúng tôi, phân nhóm nguyên nhân lấp mạch từ tim có liên quan độc lập làm tăng nguy cơ đột quỵ tái phát với $H R=1,85$; $p$ $=0,032$. Kết quả này phù hợp với nhiều nghiên cứu khác. Trước hết, nghiên cứu của Xu và cộng sự với $\mathrm{HR}=2.55$ cho thấy lấp mạch từ tim làm tắng nguy cơ tái phát đột quy.[8]. Kế đến là nghiên cứu của Soda và cộng sự thấy rằng trong số những bệnh nhân đột quỵ tái phát thì lấp mạch từ tim chiếm tỉ lệ cao nhất so với các phân nhóm còn lại $(14,4 \%)$ và sự khác biệt này có ý nghĩa thống kê.

Dùng thuốc statin sau ra viện: Kết quả từ nghiên cứu của chúng tôi cho thấy liệu pháp statin là yếu tố làm giảm nguy cơ tái phát đột quy. với $H R=0,62 ; p=0,016$. Kết quả này giống với kết quả của nghiên cứu SPARCL. Nghiên cứu này đã chứng minh hiệu quả trong viêcc giảm nguy cơ đột quy tái phát mà không có bất kỳ rủi ro đáng kể nào về xuất huyết nội so. Bên cạnh, tác giả Lee và cộng sự thấy rằng việc ngưng dùng statin sau ra viện sể làm tăng nguy cơ đột quy tái phát với $H R=1,42$ [4].Ngoài ra, tác giả Laloux và cộng sự cũng thấy statin làm giảm được nguy cơ tái phát đột quy. Statin rất cần thiết trong phòng ngừa đột quy tái phát bởi lẽ ngoài việc điều chỉnh rối loạn lipid máu, statin còn ổn định mảng xơ vữa, cải thiện chức năng tê bào nội mạc, chống viêm, chống kết tập tiểu cầu, giảm nguy cơ lấp mạch từ tim [3].

\section{KẾT LUẬN}

Tại thời điểm 1 năm sau đột quy thiếu máu não cấp, tỷ suất tái phát đột quy tích lũy là $21,2 \%$. Các yếu tố liên quan độc lập làm tăng nguy cơ đột quy. tái phát là trình độ học vấn $<6$ năm (tiểu học trở xuống), tiền sử đột quy./TIA, tiền sử nhồi máu cơ tim, rung nhĩ và lấp mạch từ tim. Yếu tố liên quan độc lập làm giảm nguy cơ tái phát đột quỵ là dùng thuốc statin.

\section{TÀI LIÊUU THAM KHẢO}

1 M. Alter, S. M. Lai, G. Friday, et al.(1997) "Stroke recurrence in diabetics. Does control of blood glucose reduce risk?", Stroke. 28(6), pp. 1153-7.

2 M. Alter, E. Sobel, R. L. McCoy, et al.(1987), "Stroke in the Lehigh Valley: risk factors for recurrent stroke", Neurology. 37(3), pp. 503-7. 
3 P. Laloux.(2013), "Risk and benefit of statins in stroke secondary prevention", Curr Vasc Pharmacol. 11(6), pp. 812-6.

4 M. Lee, J. L. Saver, Y. L. Wu, et al.(2017), "Utilization of Statins Beyond the Initial Period After Stroke and 1-Year Risk of Recurrent Stroke", J Am Heart Assoc. 6(8), pp.

5 S. Melkas, G. Sibolt, N. K. Oksala, et al.(2012),"Extensive white matter changes predict stroke recurrence up to 5 years after a first-ever ischemic stroke", Cerebrovasc Dis. 34(3), pp. 191-8.
6 K. M. Mohan, C. D. Wolfe, A. G. Rudd, et al.(2011),"Risk and cumulative risk of stroke recurrence: a systematic review and metaanalysis", Stroke. 42(5), pp. 1489-94.

7 S. Penado, M. Cano, O. Acha, et al.(2003),"Atrial fibrillation as a risk factor for stroke recurrence", Am J Med. 114(3), pp. 206-10.

8 G. Xu, X. Liu, W. Wu, et al.(2007),"Recurrence after ischemic stroke in chinese patients: impact of uncontrolled modifiable risk factors", Cerebrovasc Dis. 23(2-3), pp. 117-20.

\section{ĐĂC ĐIỂM RỐI LOẠN CƯƠNG DƯƠ'NG Ở BỆNH NHÂN TĂNG SINH LÀNH TÍNH TUYẾN TIỀN LIỆT Có CHỈ ĐỊNH PHẪU THUÂTT}

\section{TÓM TẮT}

Mục tiêu nghiên cứu:mô tả đặc điểm rối loạn cương dươngở bệnh nhân tăng sinh lành tính tuyến tiền liệt có chỉ định phẫu thuật và xác định một số yếu tố ảnh hưởng. Đối tượng và phương pháp nghiên cứu: Nghiên cứu mô tả cắt ngang trên 110 nam bệnh nhân được chẩn đoán xác định tăng sinh lành tính tuyến tiền liệt có chỉ định can thiệp phẫu thuật tại khoa Ngoại tiết niệu bệnh viện Trung ương Thái Nguyên. Kết quả: Tuổi trung bình $66,4 \pm 7,3$; 85,5\%;Bệnh kèm theo: bệnh tim mạch 23,6\%, tăng huyết áp $29,1 \%$, đái tháo đường $37,3 \%$; lí do vào viện vì đái khó $69,1 \%$, đái nhiêu lần $39,1 \%$, bí đái $5,5 \%$, đái máu 3,6\%; điểm IIEF trung bình $17,8 \pm$ 5,8; điểm IPSS trung bình $22,5 \pm 3,9$. Có ảnh hưởng giữa tuổi cao, bệnh lí kèm theo và tình trạng rối loạn tiểu tiện với $R L C D(p<0,05, p<0,05$ và $p<0,001)$. Kết luận: RLCD là tình trạng phố biến ở những bệnh nhân TSLTTTL. Những yếu tố như tuổi cao, bệnh kèm theo, tình trạng rối loạn tiểu tiện có ảnh hưởng làm gia tăng tần suất và mức độ RLCD.

Tư khóa: rối loạn cưởng dương, tăng sinh lành tính tuyến tiền liệt, thang điểm IPSS, thang điểm IIEF.

\section{SUMMARY \\ CHARACTERISTICS OF ERECTILE DYSFUNCTION IN PATIENTS WITH BENIGN PROSTATIC HYPERPLASIA WHO ARE INDICATED TO SURGERY}

Objectives: The aims of the study is to describe the characteristics of erectile dysfunction in patients with benign prostatic hyperplasia who are indicated to surgery and indentify some influential factors. Study method: Across- sectional descriptive method was carried out on 110 male patients diagnosed with benign prostatic hyperplasia who are indicated to

\footnotetext{
*Trường Đại học Y Dược Thái Nguyên Chịu trách nhiệm chính: Đỗ Duy Tùng Email: dotungdhy@gmail.com Ngày nhận bài: 11.3.2021 Ngày phản biện khoa học: 10.5.2021 Ngày duyệt bài: 18.5.2021
}

\section{Đỗ Duy Tùng*, Trần Đức Quý*}

surgery in Department of Urology in Thainguyên General Hospital. Result: The average age range of the patients was from 66,4 to $\pm 7,3 ; 85,5 \%$ of patients accompanied with cardiovascular diseases; $23,6 \%$, patients with hypertension; $29,1 \%$, patients with diabetes; 37,3\%; 69,1\% patients were admitted to hospital with dysuria;39,1\%, with frequent urination; 5,5\% with urinary retention, 3,6\% with hematuria. The average IIEF score was $17,8 \pm 5,8$; the average IPSS score was $22,5 \pm 3,9$. There isa correlation between old age, comorbidities and LUTS with erectile dysfuntion ( $p<0,05, p<0,05$ and $p<$ $0,01)$. Conclusion: Erectile dysfuntion is a common condition in patients with benign prostatic hyperplasia. The factors such as old age, comorbidities, and LUTS have an effect on increasing the frequency and severity of erectile dysfuntion.

Keyword: Erectile dysfuntion, benign prostatic hyperplasia, IPSS questionnaire, IIEF questionnaire.

\section{I. ĐẶT VẤN ĐỀ}

Rối loạn cương dương (RLCD) được định nghĩa là sự không đạt được hoặc duy trì sự cương cứng của dương vật để đạt được sự thỏa mãn khi giao hợp. Tăng sinh lành tính tuyển tiền liệt (TSLTTL) là sự phát triển hoặc tăng sinh không ác tính của biểu mô tuyến tiền liệt và là nguyên nhân phổ biến của các triệu chứng đường tiểu dưới ở nam giới (LUTS)[7]. Rối loạn cương dươngvà tăng sinh lành tính tuyến tiền liệt (TSLTTTL) là những bệnh lí thường gặp ở nam giới trên 40 tuổi. Theo một nghiên cứu tổng hợp, tỉ lệ mắc RLCD là khoảng $50 \%$ ở tuổi 50 , tăng lên $70 \%$ ở tuổi 70 ; trong khi đó RLCD hoàn toàn hoặc trung bình là $9 \%$ ở nam giới từ 40-44 tuổi; $50 \%$ ở những người từ 65-70 tuổi[4]. Tỉ lê bệnh nhân TSLTTTL cũng tăng dần theo tuổi, $50-60 \%$ ở tuổi 60 , tăng lên $80-90 \%$ ở những người trên 70 tuối[7]. RLCD trên những bệnh nhân TSLTTTL đang được quan tâm nhiều trong những năm gần đây. Câu hỏi đặt ra là tình trạng 